\title{
Mutations in Arabidopsis YCF20-like genes affect thermal dissipation of excess absorbed light energy
}

\author{
Hou-Sung Jung $\cdot$ Krishna K. Niyogi
}

Received: 5 November 2009/Accepted: 5 January 2010/Published online: 20 January 2010

(C) The Author(s) 2010. This article is published with open access at Springerlink.com

\begin{abstract}
Plants dissipate excess absorbed light energy as heat to protect themselves from photo-oxidative stress. The Arabidopsis thaliana npq6 mutant affected in thermal dissipation was identified by its partial defect in the induction of nonphotochemical quenching of chlorophyll fluorescence (NPQ) by excess light. Positional cloning revealed that $n p q 6$ contains a frameshift mutation caused by a single base-pair deletion in the At5g43050 gene, which encodes a member of the hypothetical chloroplast open reading frame 20 (YCF20) family of proteins with unknown function(s). The YCF20 protein family is mostly conserved in oxygenic photosynthetic organisms including cyanobacteria, eukaryotic algae, and plants. Amino acid sequence comparison identified two other genes in Arabidopsis that encode similar proteins to NPQ6: At1g65420 and At3g56830. These three Arabidopsis proteins have functional chloroplast-targeting transit peptides. Using reverse genetics, a mutant with a T-DNA insertion within the Atlg65420 gene was identified and shown to exhibit a low NPQ phenotype similar to that of $n p q 6$; therefore,
\end{abstract}

Electronic supplementary material The online version of this article (doi:10.1007/s00425-010-1098-9) contains supplementary material, which is available to authorized users.

H.-S. Jung · K. K. Niyogi ( $\varangle)$

Department of Plant and Microbial Biology,

University of California, Berkeley, CA 94720-3102, USA

e-mail: niyogi@berkeley.edu

Present Address:

H.-S. Jung

Plant Biology Laboratory, Salk Institute,

La Jolla, CA 92037, USA

K. K. Niyogi

Physical Biosciences Division, Lawrence Berkeley National

Laboratory, Berkeley, CA 94720, USA
Atlg65420 was named NPQ7. In contrast, a knockdown mutant in the At3g56830 gene with lower transcript levels showed wild-type levels of NPQ. The npq6 npq7 double mutant had an additive NPQ defect, indicating that the YCF20 family members in Arabidopsis have overlapping functions affecting thermal dissipation.

Keywords Arabidopsis thaliana .

Chlorophyll fluorescence $\cdot$ Nonphotochemical quenching · NPQ6 - NPQ7 · Photosynthesis · YCF20

$\begin{array}{ll}\text { Abbreviations } \\ \text { A } & \text { Antheraxanthin } \\ \text { NPQ } & \text { Nonphotochemical quenching } \\ \text { qE } & \text { Energy-dependent component of NPQ } \\ \text { RACE } & \text { Rapid amplification of cDNA ends } \\ \text { V } & \text { Violaxanthin } \\ \text { VDE } & \text { Violaxanthin de-epoxidase } \\ \text { Z } & \text { Zeaxanthin }\end{array}$

\section{Introduction}

Plants need light energy to drive photosynthesis. However, too much light can cause photo-oxidative damage (Barber and Andersson 1992; Long et al. 1994); therefore, plants have to avoid or overcome the damage in order to perform photosynthesis efficiently. To deal with light stress, plants have evolved several defense mechanisms (Niyogi 1999) that are involved in acclimation to excess light ( $\mathrm{Li}$ et al. 2009). For example, a decrease in light energy absorption can be achieved under high light by chloroplast avoidance movement, which protects plants from photo-oxidative 
stress (Kasahara et al. 2002). In addition, excess absorbed light energy can be quenched and harmlessly dissipated as heat (Horton et al. 1994; Niyogi 1999). By this thermal dissipation, over $75 \%$ of absorbed photons can be eliminated (Demmig-Adams et al. 1996).

The thermal dissipation can be quantified by measuring nonphotochemical quenching of chlorophyll fluorescence (NPQ) (Baker 2008). NPQ is rapidly induced by excess light and is relaxed in the dark. Energy-dependent quenching (qE), state-transition quenching (qT) and photoinhibitory quenching $(\mathrm{qI})$ are three components that constitute NPQ, and each component is distinguishable based on its relaxation kinetics (reviewed in Maxwell and Johnson 2000; Müller et al. 2001). There are also differences in the degree of contribution of each component to NPQ in different organisms. For instance, in some cyanobacteria, qT can be a major component of NPQ (Campbell et al. 1998), whereas others exhibit a substantial rapid component (Bailey et al. 2005). In higher plants, most of the NPQ is often qE (Maxwell and Johnson 2000).

It has been previously demonstrated that a high proton gradient across the thylakoid membrane is required for $\mathrm{qE}$ (Briantais et al. 1979). Induction of $\mathrm{qE}$ also requires zeaxanthin $(\mathrm{Z})$ synthesis through antheraxanthin (A) from violaxanthin (V) by violaxanthin de-epoxidase (VDE), an enzyme that is activated by low $\mathrm{pH}$ in the thylakoid lumen (Yamamoto et al. 1962). The de-epoxidation state $(\mathrm{A}+\mathrm{Z}) /(\mathrm{V}+\mathrm{A}+\mathrm{Z})$, is closely correlated with NPQ (Demmig-Adams and Adams 1996), and Arabidopsis thaliana mutants affecting VDE exhibit much less $\mathrm{qE}$ than the wild-type (Niyogi et al. 1998). Molecular genetic analyses in Arabidopsis have also revealed that the PsbS (NPQ4) protein of photosystem II (PSII) is a critical factor for $\mathrm{qE}$ (Li et al. 2000) and that efficient $\mathrm{qE}$ needs specific organization of the PSII light-harvesting antenna (Kovacs et al. 2006). Most, if not all, of the single gene mutants in Arabidopsis that have a major effect on NPQ without impairing photosynthetic electron transport have already been identified in previous studies. Thus, the next phase of genetic analysis of NPQ will require the screening and characterization of $n p q$ mutants with more subtle phenotypes, along with the identification of quantitative trait loci that affect NPQ (Jung and Niyogi 2009).

In this study, we used forward and reverse genetic approaches to discover that mutations in YCF20-like genes affect thermal dissipation of excess absorbed light energy in Arabidopsis. In a forward genetic screen, we isolated a new low NPQ mutant, npq6, and then identified the NPQ6 gene as a member of the YCF2O family. Using a reverse genetic approach, we analyzed a T-DNA insertion allele of another YCF20-like gene, which we called $N P Q 7$ based on its mutant phenotype. The additive phenotype of an $n p q 6$ $n p q 7$ double mutant suggests that YCF20-like proteins have overlapping functions affecting NPQ.

\section{Materials and methods}

Plant materials and growth conditions

The npq6 mutant was isolated from fast-neutron-mutated Arabidopsis thaliana $\mathrm{M}_{2}$ seeds (Col-3 gll). The $\mathrm{M}_{2}$ seeds and wild-type Col-3 gll seeds were obtained from Lehle Seeds (Round Rock, TX). The Atlg65420 knockout and the At3g56830 knockdown mutants were identified from $\mathrm{T}_{3}$ seeds of the SALK_010998 and SALK_021029 lines, respectively (Alonso et al. 2003). Both SALK_010998 and SALK_021029 were obtained from the Arabidopsis Biological Resource Center (ABRC).

Arabidopsis plants were grown in a light(150 $\mu \mathrm{mol}$ photons $\left.\mathrm{m}^{-2} \mathrm{~s}^{-1}\right)$ and temperature-controlled $\left(22^{\circ} \mathrm{C}\right)$ growth chamber after $2-3$ days of stratification at $4^{\circ} \mathrm{C}$. For chlorophyll fluorescence measurements and pigment analysis, plants were grown in a short-day condition (10 h light/14 h dark) for 5-6 weeks. For other experiments, plants were grown in a long-day condition $(16 \mathrm{~h}$ light/8 h dark).

Digital video imaging and chlorophyll fluorescence measurements

For digital video imaging of chlorophyll fluorescence, seedlings were grown on MS-salt (Gibco, Grand Island, $\mathrm{NY})$ agar plates in a light- $\left(80 \mu \mathrm{mol}\right.$ photons $\left.\mathrm{m}^{-2} \mathrm{~s}^{-1}\right)$ and temperature-controlled $\left(22^{\circ} \mathrm{C}\right)$ growth chamber for 10-14 days. Following dark adaptation for $30 \mathrm{~min}, \mathrm{NPQ}$ images were acquired using a video imaging system (Niyogi et al. 1997; Niyogi et al. 1998) controlled by IP lab software (Scanalytics Inc., Fairfax, VA).

An FMS2 fluorometer (Hansatech, King's Lynn, UK) was used to measure chlorophyll fluorescence parameters from attached rosette leaves. For NPQ measurement, leaves were dark-adapted for $2 \mathrm{~h}$ and then exposed to actinic illumination $\left(1,500 \mu \mathrm{mol}\right.$ photons $\left.\mathrm{m}^{-2} \mathrm{~s}^{-1}\right)$ for $10 \mathrm{~min}$ followed by darkness for $5 \mathrm{~min}$. The maximum fluorescence levels after dark adaptation $\left(F_{\mathrm{m}}\right)$ and in the light-adapted condition $\left(F_{\mathrm{m}}^{\prime}\right)$ were measured by applying a saturating pulse of light. NPQ was calculated as $\left(F_{\mathrm{m}}-F_{\mathrm{m}}^{\prime}\right) / F_{\mathrm{m}}^{\prime}$. For ETR estimation, plants were treated with a series of increasing light intensities. During each illumination, the steady-state fluorescence $\left(F_{\mathrm{s}}\right)$ was determined, and $F_{\mathrm{m}}^{\prime}$ was measured by applying a saturating pulse of light. The quantum yield of PSII ( $\Phi_{\text {PSII }}$ ) was calculated as $\left(F_{\mathrm{m}}^{\prime}-F_{\mathrm{s}}\right) / F_{\mathrm{m}}^{\prime}$ (Genty et al. 1989). 
Pigment analysis

Leaf disks (diameter of $8 \mathrm{~mm}$ ) were obtained from rosette leaves and treated in high light $(1,700 \mu \mathrm{mol}$ photons $\mathrm{m}^{-2} \mathrm{~s}^{-1}$ ) on top of water for 5,10 and $30 \mathrm{~min}$. Leaf disks were ground to a fine powder in liquid nitrogen. Pigments were extracted from the powder with $150 \mu \mathrm{l}$ of $100 \%$ acetone. Following additional extraction with $150 \mu \mathrm{l}$ of $100 \%$ acetone, cell debris was pelleted by centrifugation, and supernatants were subjected to HPLC (MüllerMoulé et al. 2002). The results were analyzed using a twoway ANOVA function in MS-Excel (Microsoft Corp., Seattle, WA).

\section{Positional cloning and complementation}

An npq6 mapping population was constituted from $\mathrm{F}_{2}$ plants of $n p q 6 \times$ Ler crosses. Low NPQ $\mathrm{F}_{2}$ plants were selected using the digital video imaging system. To determine genotypes, genomic DNA was extracted using an alkali method (Klimyuk et al. 1993).

PCR information for SSLP markers was obtained from the Arabidopsis Information Resource (TAIR). Polymorphisms published in the Cereon Arabidopsis polymorphism collection (now Monsanto Arabidopsis Polymorphism and Ler Sequence Collection) (Jander et al. 2002) were utilized for polymorphic marker generation, and primers were designed using the web-based Primer3 program (Rozen and Skaletsky 2000). The names of new markers generated in this study were coined in the following order: BAC clone name and marker type ( $i$ for IN/DEL and $\mathrm{c}$ for CAPS) followed by number to distinguish markers of the same type on the same BAC clone.

Near SO191, two IN/DEL markers MJB21i1 (F: 5'-C CCAACAGCAACCTCAAGTA-3'; R: 5'-TCCGAAACC AAACTTGAGAAA-3') and MJB21i2 (F: 5'-TTCTTA CCATTGGCCTTTGC-3'; R: 5'-TCGGCGATTATCTA AATTGTCC- $3^{\prime}$ ) were generated based on 25 and $13 \mathrm{bp}$ insertion polymorphisms in Col. In MBD2, another IN/ DEL marker MBD2i (F: 5'-TTTGCACTCTATGCT GCTGG-3'; R: 5'-AAGCTCATCCTTGGTGATGG-3') showing 12 bp deletion polymorphism in Col was developed, and the genotypes were determined following separation of PCR products on 3\% agarose gels.

From the bottom side of chromosome 5, two IN/DEL markers K9L2i (F: 5'-GCGTATGGCAATATCAGGGT-3'; R: $\quad 5^{\prime}$-TCAAAACTATATCAATCGAAAGCA-3'), and K9D7i (F: 5'-TGGTTTCTTCGTCTTTTGTGC-3'; R: 5'-A ACAGCAAGAGTTGCGAGGT-3') were designed based on 27 and 23 bp polymorphisms between Col and Ler, respectively. Additionally, CAPS markers MBD2c (F: 5'-T TGTCTTGTGACTGAGGCTTG-3'; R: 5'-CCTGTTTCT GTTTCTGATTTTCC-3'), MMG4c1 (F: 5'-GAACAGCC
AAAAGACCAAGC-3'; R: 5'-AGTGACCTAACGCCCT AACG-3'), and MMG4c2 (F: 5'-ACATCGTCGGTCTCT GTTCC-3'; R: 5'-CATTAGATTAGCGGGTGTAGGG-3') were developed. The PCR product of MBD2c, MMG4c1, and MMG4c2 were digested with MseI, MscI, and DraI, respectively, and then resolved in $2 \%$ agarose gels.

The E43050d marker was developed based on a mismatch selected in dCAPS Finder 2.0 (Neff et al. 2002). In the reverse primer (5'-TTCCGAAACTCTGGCcCTG ATG-3'), a mismatch nucleotide, the lower case c, was incorporated to generate a $B s l$ I restriction sequence only if wild-type genomic DNA was used as a template in a PCR reaction with the forward primer $\left(5^{\prime}\right.$-GCAGCAACCAATGATGAATATGG-3'). Following BslI digestion, PCR products were resolved in $3 \%$ agarose gels.

For complementation, the genomic DNA region encompassing the NPQ6 gene was amplified using PfuTurbo DNA polymerase (Stratagene, La Jolla, CA) with HS50g2F $\left(5^{\prime}-\mathrm{T}\right.$ TCCAGCTGTCTCGTCACC-3') and HS50g2R (5'-GC TGATGGTCGTTGTGACC-3' ${ }^{\prime}$ ). The $5.3 \mathrm{~kb}$ PCR product was digested with EcoR I and HindIII and then ligated into pPZP121 digested with EcoRI and HindIII. This vector pHS503 was introduced into the npq6 mutant using the Agrobacterium-mediated floral dip method (Clough and Bent 1998). $\mathrm{T}_{1}$ seeds were selected on MS-salt containing gentamycin $(100 \mu \mathrm{g} / \mathrm{ml})$ and carbenicillin $(100 \mu \mathrm{g} / \mathrm{ml})$, and resistant plants with true leaves were transplanted to score NPQ levels. Similar procedures were used for complementation of $n p q 6$ by the NPQ6 cDNA except that the $35 \mathrm{~S}$ promoter was used instead of the NPQ6 native promoter.

\section{Localization of GFP fusion proteins}

The Arabidopsis coding regions encoding 44, 68 and 59 N-terminal amino acids of NPQ6, At1g65420 (NPQ7) and At3g56830, respectively, were amplified and ligated to

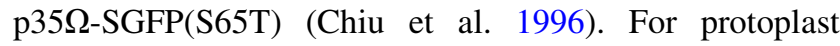
preparation, young Arabidopsis leaves (ecotype Col-0) from plants grown on soil were used. Two grams fresh weight of aerial tissues were suspended in $30 \mathrm{ml}$ of a buffer containing $1 \%(\mathrm{w} / \mathrm{v})$ cellulase Onozuka R-10; $0.26 \%$ Macerozyme R-10 (Karlan Research Product, Santa Rosa, CA), 0.4 M mannitol, $20 \mathrm{mM} \mathrm{KCl,} 20 \mathrm{mM}$ MES, pH 5.7, $10 \mathrm{mM} \mathrm{CaCl}_{2}, 0.1 \% \mathrm{BSA}$, vacuum infiltrated for $1 \mathrm{~min}$, and incubated for $3 \mathrm{~h}$ at room temperature with gentle shaking. The clear digest was filtered through a $35 \mu \mathrm{M}$ nylon mesh (Carolina Biological Supply, Burlington, NC), and the protoplasts were harvested by centrifugation for $2 \mathrm{~min}$ at $200 \mathrm{~g}$ and washed twice in $20 \mathrm{ml}$ of W5 wash solution $(154 \mathrm{mM} \mathrm{NaCl}, 125 \mathrm{mM} \mathrm{CaCl}, 5 \mathrm{mM} \mathrm{KCl}$, $2 \mathrm{mM}$ MES pH 5.7). The pellet was suspended in $1 \mathrm{ml}$ of mannitol/Mg solution (15 mM $\mathrm{MgCl}_{2}, 0.4 \mathrm{M}$ mannitol, $4 \mathrm{mM}$ MES, pH 5.7). Protoplasts were counted using a 
haemocytometer, and their concentration was adjusted to $4.0 \times 10^{5}$ cells $\mathrm{ml}^{-1}$ with mannitol/Mg solution. Ten micrograms (in $10 \mu \mathrm{l}$ ) of plasmid DNA and $110 \mu \mathrm{l}$ of polyethylene glycol (PEG) solution (40\% PEG 4000, $0.2 \mathrm{M}$ mannitol, $0.1 \mathrm{M} \mathrm{CaCl}_{2}$ ) were added to $100 \mu \mathrm{l}$ of the protoplast solution, very gently mixed, and left for $30 \mathrm{~min}$ at room temperature. The solution was very slowly diluted with $440 \mu \mathrm{l}$ of W5 solution and then pelleted by centrifugation for $2 \mathrm{~min}$ at $200 \mathrm{~g}$. Protoplasts were further resuspended in $\mathrm{W} 5$ solution, and left at $23^{\circ} \mathrm{C}$ for $16 \mathrm{~h}$ under continuous light. Green fluorescence and chlorophyll red autofluorescence images were monitored using a confocal laser scanning microscope (FVX-IHRT Fluoview Confocal LSM, Olympus). The green fluorescence signals were detected at $530 \mathrm{~nm}$ following $\mathrm{Kr} / \mathrm{Ar}$ laser excitation $(488 \mathrm{~nm})$; and the chlorophyll autofluorescence signals were detected using the Cy5 filter set.

Sequence analysis and alignment

Prior to amino acid sequence alignment, the cleavage sites of chloroplast transit peptides were predicted using the ChloroP program (Emanuelsson et al. 1999; Nielsen et al. 1997). Following removal of the chloroplast transit peptides, the Clustal_X and the BOXSHADE (http://www.ch. embnet.org/software/BOX_form.html) programs were used for amino acid sequence alignment and its display, respectively (Thompson et al. 1997). In the Clustal_X program, the gap opening penalty and gap extension penalty under pairwise and multiple alignment parameter options were adjusted to minimize the number and size of gaps in the amino acid sequence alignment.

Phylogenetic tree generation

To generate an unrooted phylogenetic tree, the C-terminal 71 amino acids of YCF20-like proteins were used because the C-terminal region appeared to be more highly conserved than the N-terminal region and the shortest YCF20like protein (encoded by the chloroplast genome in Cyanidioschyzon merolae) is 71 amino acids. Amino acid sequence alignment followed by neighbor-joining tree generation was performed using programs available in http://align.genome.jp/.

Identification of the $n p q 7$ T-DNA insertion

Seeds of SALK_010998 were germinated on MS-media plates without kanamycin. Homozygous lines for T-DNA insertion were screened using PCR with Atlg65420 genespecific primers A (5'-CGTTTGCGTTAGACACTGG T-3 $\left.3^{\prime}\right)$, B (5'-TGACACTTGTGAACCTCCAAA- $\left.3^{\prime}\right)$ and a T-DNA left border-specific primer (LBa1 or LBb1;
http://signal.salk.edu/pBIN-pROK2.txt-new). For the $n p q 6$ $n p q 7$ double mutant screening, At 1 g65420 gene-specific primers E ( $5^{\prime}$-TGCGTTTTGATTTTCTGCAC- $\left.3^{\prime}\right)$ and $\mathrm{F}$ (5'-ATCTCGCAGTTTGCTACAGG-3') were used. For RT-PCR, RNA was extracted using the RNeasy plant mini kit (Qiagen, Valencia, CA), and reverse transcription (RT) reactions were performed using the ImProm-II reverse transcription system (Promega, Madison, WI). Following the $\mathrm{RT}$ reaction, cDNA was amplified for 30 cycles using Atlg65420 gene-specific primers C (5'-GCTTCGTCCAT TACTCTCACTTC- $\left.3^{\prime}\right)$ and D (5'-CTAAGCAAACACC AGCTTTCC- $3^{\prime}$ ). For complementation of the At $1 g 65420$ knockout (npq7) mutant, a $5.5 \mathrm{~kb}$ genomic DNA region encompassing the At1g65420 gene was amplified using PfuTurbo DNA polymerase (Stratagene, La Jolla, CA) with 65420comp4F (5'-TACTTAGATGCCAAAGGTCCAA G-3') and 65420comp2R (5'-CTCACAGGTATTTCAGA GTGCAG- $3^{\prime}$ ). The PCR product was digested with KpnI and BamHI and then ligated into pPZP121 digested with $K p n I$ and BamHI. This vector pHS203 was introduced into the $n p q 7$ mutant as described above for complementation of $n p q 6$.

Identification of the At3g56830 T-DNA insertion

The At3g56830 gene-specific primers I (5'-TAATAG ATTCCGGCGTGGAC-3') and II (5'-GAGGGAACAA ATGGCAAGAG-3') with LB primer were used for homozygous T-DNA insertion line screening from SALK_021029. For quantitative RT-PCR, the At3g56830 gene-specific primers III $\left(5^{\prime}\right.$-CTTGCCTAAAAGGAG TTTCAGAG-3') and IV (5'-GCGAGTCCAGTCTTCC AATAG-3') were used. As a quantitative control, polyubiquitin (UBQ10: At4g05320) gene-specific primers (F: 5'-GATCTTTGCCGGAAAACAATTGGAGGATGGT-3'; R: 5'-CGACTTGTCATTAGAAAGAAAGAGATAACAG G- $3^{\prime}$ ) were used. In each PCR, products were amplified 25 times.

$5^{\prime}$ - and $3^{\prime}$-rapid amplification of cDNA ends (RACE)

RACE PCR reactions were performed using the SMART RACE cDNA amplification kit (BD Biosciences, Palo Alto, CA), and RNA was isolated using the RNeasy plant mini kit (Qiagen, Valencia, CA). Following second PCR reactions with gene-specific nested primers, PCR products were ligated to pGEM-T Easy vector (Promega, Madison, WI) for DNA sequence determination.

For NPQ6 5'-RACE, E43050 gene-specific primer 1 (E43050GSP1) (5'-GCCAGCTTGAAGGCGTCAATGA AGAGA-3') and E43050 nested gene-specific primer 1 (E43050NGSP1) (5'-CGCATAGAACCGCAGCAATAAC ATCG-3') were used. For NPQ6 3'-RACE, E43050GSP2 
Fig. 1 Nonphotochemical quenching of chlorophyll fluorescence (NPQ) in $n p q 6, n p q 7$ and $n p q 6 n p q 7$. NPQ values were measured on attached rosette leaves using an FMS2 fluorometer during actinic illumination $\left(1,400 \mu \mathrm{mol}\right.$ photons $\left.\mathrm{m}^{-2} \mathrm{~s}^{-1}\right)$ for $10 \mathrm{~min}$ followed by relaxation in the dark for $5 \mathrm{~min}$. a NPQ values in the Col-3 gll (wildtype) and $n p q 6$ (in the Col-3 gll background). b NPQ values in wildtype (WT) segregants and homozygous T-DNA insertion lines (npq7) of SALK_010998. c NPQ values in wild-type (GL1), npq6 (GL1), $n p q 7$ (GL1) and the $n p q 6 n p q 7$ (GL1) double mutant, which were isolated from segregating population of $n p q 6$ (in the Col-3 gll background) and $n p q 7$ (in the Col-0 background) crosses. Each data point represents the mean $\pm \mathrm{SD}(n=2-4)$

(5'-TGCCAGAGTTTCGGAACGTTTGTGTCG-3') and E43050NGSP2 (5'-CAAGAGACTGAAGGTCCAACGCC AAGA-3') were used. For the At3g56830 gene 5'-RACE, C56830GSP1 (5'-AACAGTCCCAGGGCGAGTCCAGTC TT-3') and C56830NGSP1 (5'-ATGGTGATCGTGCTC CGCATCTTGTT) were used. For the At3g56830 gene 3'-RACE, C56830GSP2 (5'-AAAGCTCGGTTGGTGGG GACAGATTC- $\left.3^{\prime}\right)$ and C56830NGSP2 (5'-GCTCCAGAG GTCTACGGCTAATCAAAGC-3') were designed.

\section{Results}

Low NPQ phenotype of the npq6 mutant

The npq6 mutant was isolated as a low NPQ mutant by chlorophyll fluorescence video imaging of fast neutronmutated Arabidopsis $\mathrm{M}_{2}$ plants during exposure to excess light. Quantitative NPQ measurements confirmed that the npq6 mutant exhibits less NPQ than the wild-type (Col-3 gll, the genetic background of $n p q 6)$ during $10 \mathrm{~min}$ of actinic light illumination (Fig. 1a). The biggest differences in NPQ between $n p q 6$ and the wild-type occurred in the induction phase of NPQ (Fig. 1a). The NPQ in $n p q 6$ and the wild-type reversed rapidly (within $1 \mathrm{~min}$ ) in the dark to the same low value (Fig. 1a), indicating that it is the $q E$ component of NPQ that is affected in the mutant. Except for the lower NPQ levels in excess light, there were no visible phenotypes of $n p q 6$ (data not shown). In addition, $n p q 6$ had wild-type levels of the maximum quantum yield of PSII $\left(F_{\mathrm{v}} / F_{\mathrm{m}}\right)$, chlorophyll $a+b$ contents, chlorophyll $a /$ $b$ ratio and the xanthophyll cycle pigment $(\mathrm{V}+\mathrm{A}+\mathrm{Z})$ pool size (Table 1). These results reflect that both light energy absorption and its utilization are still functional in $n p q 6$, whereas dissipation of excess energy is impaired.

We tested whether there were any significant differences in previously identified NPQ factors between $n p q 6$ and the wild-type (Col-3 gll). Photosynthetic electron transport in high light generates a high proton gradient across the thylakoid membrane. To see whether the electron transport was affected in $n p q 6$, we measured the quantum yield of PSII $\left(\Phi_{\text {PSII }}\right)$ as a function of light intensity. The npq6 mutant
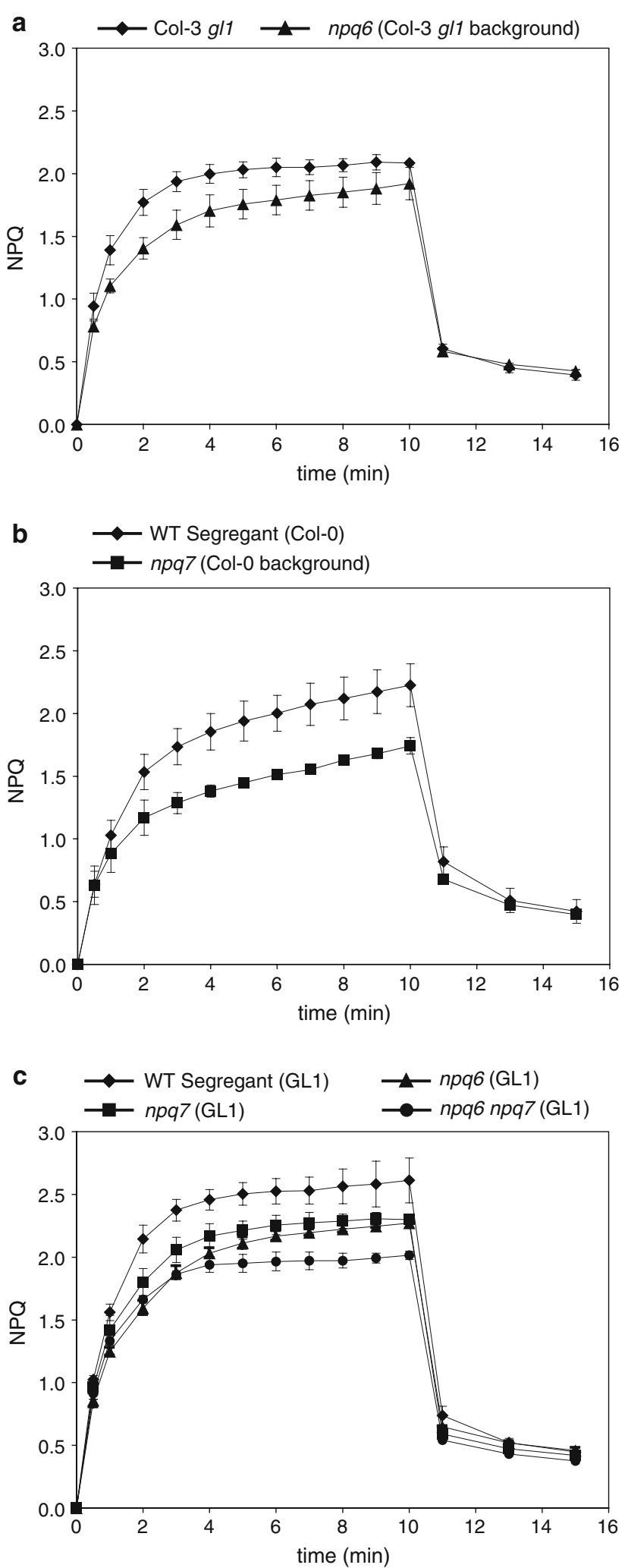

showed wild-type levels of $\Phi_{\mathrm{PSII}}$ indicating that there is no major impairment of photosynthetic electron transport in $n p q 6$ (Fig. 2a). We also treated leaf disks of $n p q 6$ and the wild-type in high light $\left(1,700 \mu \mathrm{mol}\right.$ photon $\left.\mathrm{m}^{-2} \mathrm{~s}^{-1}\right)$ for 5 , 
Table 1 Photosynthetic phenotypes of $n p q 6$ and $n p q 7$

\begin{tabular}{lllll}
\hline & $F_{\mathrm{v}} / F_{\mathrm{m}}$ & $\mathrm{Chl} a+b\left(\mu \mathrm{mol} / \mathrm{cm}^{2}\right)$ & $\mathrm{Chl} a / b(\mathrm{~mol} / \mathrm{mol})$ & $\mathrm{V}+\mathrm{A}+\mathrm{Z}(\mathrm{mmol} / \mathrm{mol} \mathrm{Chl} a)$ \\
\hline Col-3 gll & $0.829 \pm 0.006$ & $66.6 \pm 7.0$ & $2.96 \pm 0.07$ & $64.9 \pm 8.6$ \\
$n p q 6(\mathrm{Col}-3 \mathrm{gll})$ & $0.823 \pm 0.004$ & $71.4 \pm 10.4$ & $2.99 \pm 0.05$ & $67.8 \pm 9.0$ \\
Col-0 & $0.833 \pm 0.004$ & $31.8 \pm 2.6$ & $3.10 \pm 0.10$ & $66.5 \pm 8.8$ \\
$n p q 7$ (Col-0) & $0.837 \pm 0.003$ & $36.7 \pm 0.9^{*}$ & $2.75 \pm 0.23^{*}$ & $62.6 \pm 5.6$ \\
\hline
\end{tabular}

$* 0.01<P<0.05$, mean $\pm \mathrm{SD}(n=4)$
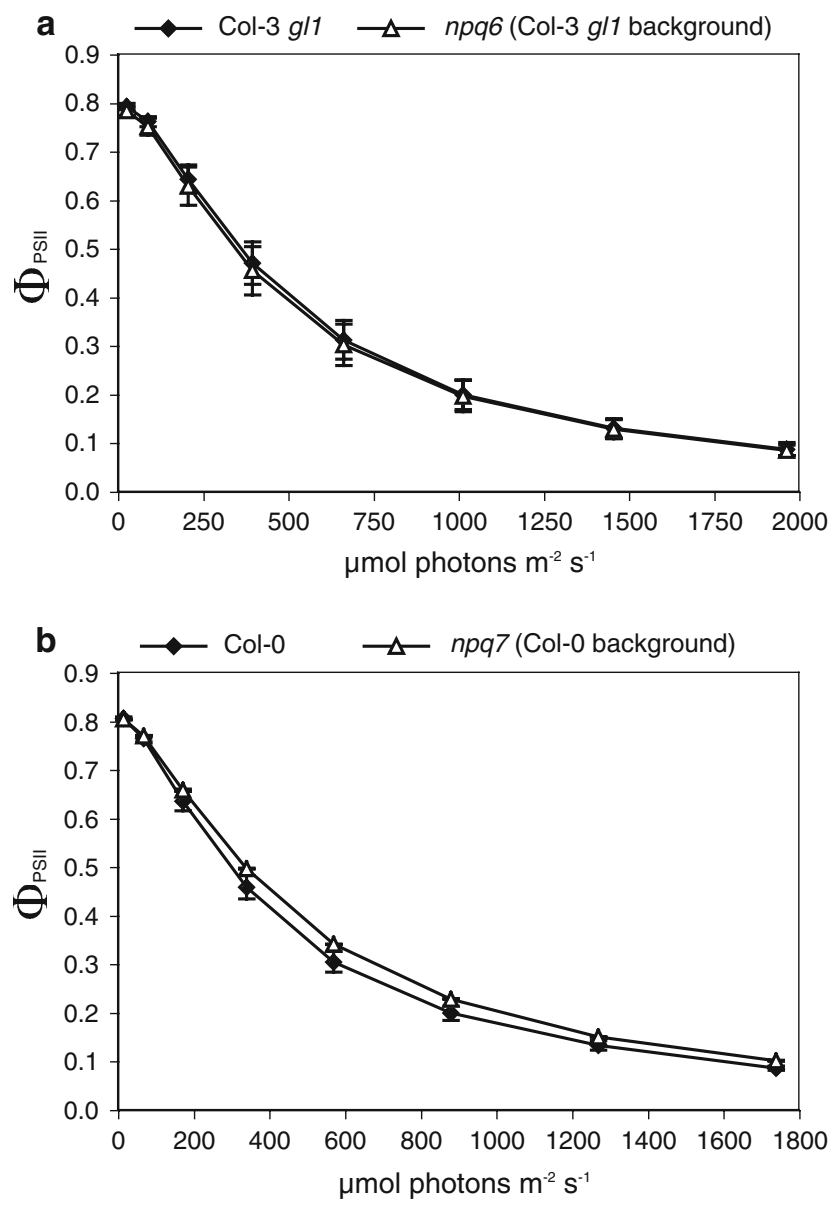

Fig. 2 Quantum Yield of PSII ( $\left.\Phi_{\mathrm{PSII}}\right)$ of $n p q 6$ and $n p q 7$. $\Phi_{\mathrm{PSII}}$ values were obtained by applying a pulse of saturating light to attached rosette leaves that had been exposed to the corresponding light intensity for $5 \mathrm{~min}$. a $n p q 6$ and wild-type (Col-3 gll) (mean $\pm \mathrm{SD}$, $\mathrm{n}=4)$. b $n p q 7$ and wild-type (Col-0) (mean $\pm \mathrm{SD}, n=2)$

10 and $30 \mathrm{~min}$ and then determined the de-epoxidation state $(\mathrm{A}+\mathrm{Z}) /(\mathrm{V}+\mathrm{A}+\mathrm{Z})$, to check whether there were any differences in VDE activity. ANOVA tests showed that high light treatment effects were significant $(P=3.35 \times$ $\left.10^{-24}\right)$. However, there were no significant differences in the de-epoxidation state between npq6 and Col-3 gll $(P>0.01)$ (Fig. 3a), indicating that $\mathrm{Z}$ synthesis is not affected in $n p q 6$. In addition, we could not find any significant interactions between high light treatments and
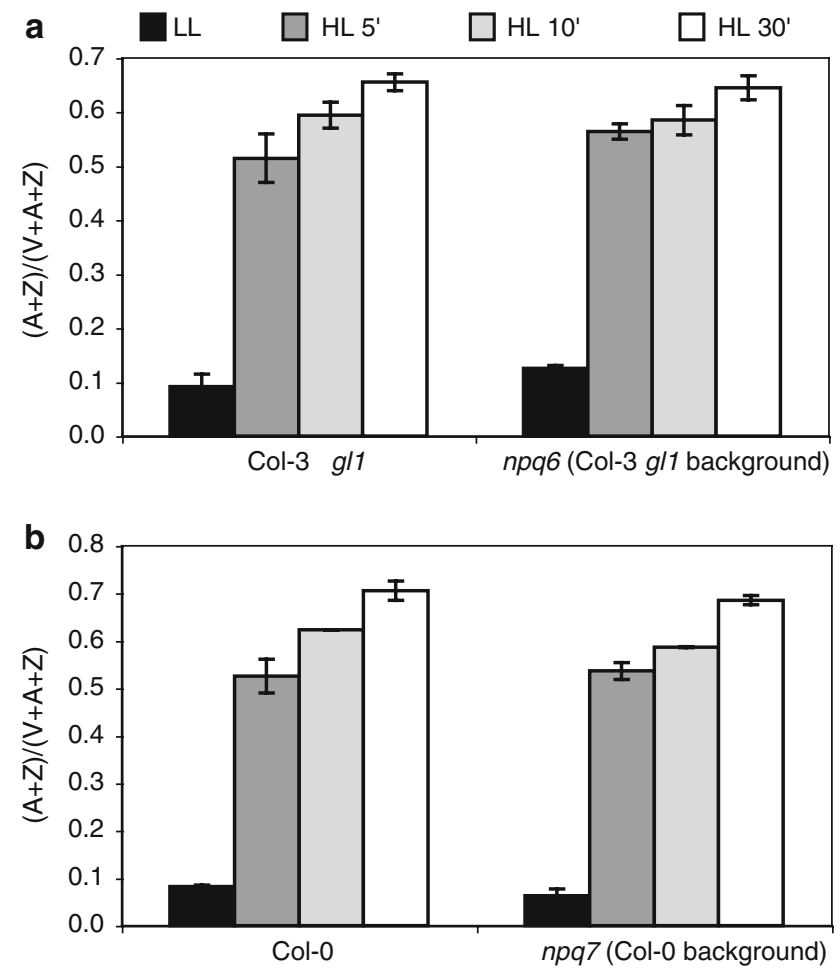

Fig. 3 Xanthophyll cycle de-epoxidation state ([A + Z]/ $[\mathrm{V}+\mathrm{A}+\mathrm{Z}])$ of $n p q 6(\mathbf{a})$ and $n p q 7(\mathbf{b})$. The amounts of violaxanthin (V), antheraxanthin (A) and zeaxanthin (Z) were determined in low light (LL $150 \mu \mathrm{mol}$ photons $\mathrm{m}^{-2} \mathrm{~s}^{-1}$ ) and after being treated in high light (HL 1,700 $\mu \mathrm{mol}$ photons $\mathrm{m}^{-2} \mathrm{~s}^{-1}$ ) for 5, 10 and $30 \mathrm{~min}$. Each data point represents the mean $\pm \mathrm{SD}(n=2-4)$

genotypes $(P>0.01)$. These results distinguish $n p q 6$ from previously characterized mutants with NPQ defects, such as the pgrl (Munekage et al. 2001) and paal (Shikanai et al. 2003) mutants affecting photosynthetic electron transport and $n p q 1$ mutants (Niyogi et al. 1998) affecting VDE.

Crosses between $n p q 6$ and the wild-type (Col-3 gll) showed that the low NPQ phenotype of $n p q 6$ is due to a single recessive nuclear mutation (Table 2). Analysis of $\mathrm{F}_{1}$ plants resulting from crosses between $n p q 6$ and $n p q 4$ (lacking the PsbS protein) showed that $n p q 6$ is not in the same complementation group as $n p q 4$ (data not shown). Taken together, these results indicate that the $n p q 6$ mutation is in a novel nuclear gene affecting NPQ, especially the early induction of NPQ at least in the Col-3 gll background. 
Table 2 Results of crosses of $n p q 6$ and $n p q 7$

\begin{tabular}{|c|c|c|c|c|c|c|}
\hline Cross & Type & Total & $\mathrm{Npq}^{+}$ & $\mathrm{Npq}^{-}$ & $\chi^{2}$ & $P$ value \\
\hline \multirow[t]{2}{*}{ NPQ6/NPQ6 $(\mathrm{Col}-3$ gll $) \times n p q 6 / n p q 6(\mathrm{Col}-3$ gll $)$} & $\mathrm{F}_{1}$ & 2 & 2 & 0 & & \\
\hline & $\mathrm{F}_{2}$ & 134 & 101 & 33 & 0.01 & 0.92 \\
\hline \multirow[t]{2}{*}{$N P Q 7 / N P Q 7(\mathrm{Col}-0) \times n p q 7 / n p q 7(\mathrm{Col}-0)$} & $\mathrm{F}_{1}$ & 2 & 2 & 0 & & \\
\hline & $\mathrm{F}_{2}$ & 40 & 27 & 13 & 1.2 & 0.27 \\
\hline
\end{tabular}

\section{Positional cloning of NPQ6}

To identify the gene affected in $n p q 6$, we conducted positional cloning. A mapping population was constituted from $\mathrm{F}_{2}$ plants of a cross between $n p q 6$ and a polymorphic wild-type strain (Ler). Approximately $50 \mathrm{~F}_{2}$ plants showing the low NPQ phenotype of $n p q 6$ were identified using the video imaging system, and their genotypes were determined using polymorphic markers including simple sequence length polymorphisms (SSLP), insertion/deletion (IN/DEL) and cleaved amplified polymorphic sequence (CAPS) markers. Using the polymorphic markers, we were able to locate the npq6 mutation on Chromosome 5. Genotyping results of the $F_{2}$ mapping population plants indicated that the mutation was in between the markers SO191 and K9L2i (Fig. 4a).

Within the interval flanked by SO191 and K9L2i, we performed fine mapping to narrow down the genomic region containing NPQ6. Near SO191, the polymorphic markers MJB21i1 and MJB21i2 detected two and one recombinants, respectively (Fig. 4a), reflecting that the mutation was in the downstream region of MJB21. From the other side, two recombinants were detected at K9D7i and one was at MMG4c1 (Fig. 4a). We developed additional polymorphic markers, MBD2c, MBD2i and MMG4c2, between MJB21i2 and MMG4c1, and found only Col genotype at each marker position (Fig. 4a). From these fine mapping results, it was determined that the mutation causing low NPQ in $n p q 6$ occurred between MJB21i2 and MMG4c1.

After reaching a genomic DNA region where only Col genotype was present, we searched for candidate genes. Because NPQ occurs in chloroplasts, we selected genes encoding chloroplast proteins using chloroplast localization prediction programs such as the ChloroP program (Emanuelsson et al. 1999). Among 33 genes located between MJB21i2 and MMG4c1, only four of them were predicted to encode chloroplast proteins with unknown function. The genomic DNA sequences encoding the four chloroplast proteins in $n p q 6$ were determined and aligned to the published sequences of Col-0. The alignment detected a single base-pair (C) deletion in a predicted exon of the At5g43050 gene (Fig. 4b). With the polymorphism caused by the deletion in $n p q 6$, we were able to develop a derived cleaved amplified polymorphic sequence (dCAPS) marker, E43050d, with the help of the dCAPS finder program (Neff et al. 2002). Using this marker, we were able to confirm the nucleotide deletion in At5g43050 of the $n p q 6$ mutant (Fig. 4e). The single nucleotide deletion causes a frame shift, because the deletion occurs within an exon, and it was predicted that a stop codon (TGA) appears in the middle of the coding region (Fig. $4 \mathrm{c}$ ). Thus, $n p q 6$ is likely to be a null mutant.

To confirm that the mutation in the NPQ6 (At5g43050) gene was responsible for the low NPQ phenotype in $n p q 6$, we did a complementation experiment by introducing the wild-type genomic DNA region encompassing NPQ6 into $n p q 6$. After obtaining antibiotic-resistant $\mathrm{T}_{1}$ plants, we examined their phenotypes using the video imaging system. In contrast to the low NPQ phenotype of $n p q 6$, the complemented $n p q 6$ plants showed a wild-type level of NPQ (Fig. 4d). Using the E43050d marker, the presence of both wild-type and mutant alleles of NPQ6 in the complemented plants was confirmed (Fig. 4e).

NPQ6 is a chloroplast protein

To determine the NPQ6 gene structure, we did rapid amplification of cDNA ends (RACE) experiments to obtain a full-length $N P Q 6$ cDNA as only a gene prediction model had been available when the gene was cloned (Fig. 4f). The alignment of RACE product sequences with genomic DNA sequences showed that the NPQ6 gene consists of two exons and an intron (Fig. 4f), which is identical to a subsequently reported full-length cDNA clone (GenBank accession number BX833464). The NPQ6 cDNA expressed under the control of the $35 \mathrm{~S}$ cauliflower mosaic virus promoter also complemented the low NPQ phenotype of $n p q 6$ (Fig. 4g), and the presence of the wild-type NPQ6 allele in the complemented plants was also demonstrated using the E43050d marker (Fig. 4h). This complementation by the cDNA corroborated the full-length cDNA cloning.

The predicted NPQ6 (At5g43050) protein consists of 158 amino acids in the precursor form and 114 amino acids in the mature form after removing $44 \mathrm{~N}$-terminal residues as the putative chloroplast transit peptide, the length of which was predicted by the ChloroP program (Emanuelsson et al. 1999; Nielsen et al. 1997). To prove that the 44 amino acid 
Fig. 4 Positional cloning of the NPQ6 gene and complementation. a Positional cloning of NPQ6 on chromosome 5. The long line is the bottom arm of chromosome 5 , and the short black bars represent BAC clones. The values in parentheses are distances between each marker position and the npq6 mutation. The number below each BAC clone marker represents the number of recombinants at each marker position. Open boxes the positions of genes encoding chloroplast proteins. b DNA sequence alignment of NPQ6. The DNA sequences of the NPQ6 (At5g43050) gene in $n p q 6$ and wild-type were aligned to show the mutation. c Predicted amino acid sequence alignment. The wild-type amino acid sequence of NPQ6 was aligned with the predicted frameshifted amino acid sequence in the $n p q 6$ mutant. Complementation of low NPQ phenotype of $n p q 6$ by genomic DNA region encompassing the NPQ6 (At5g43050) gene (d) or by the NPQ6 cDNA whose expression is driven by the $35 \mathrm{~S}$ promoter (g). Digital video imaging of chlorophyll fluorescence shows NPQ levels as pseudo-color; red for wild-type levels of NPQ and blue for low NPQ. e, h Genotyping results with the E43050d marker showed that the complemented line contained both the wild-type (lower band) and the npq6 (upper band) alleles. $\mathbf{f}$ Gene structure of NPQ6 as determined by RACE. Bars and the line exons and intron, respectively; filled bar the coding region of $N P Q 6$

residues are sufficient for protein targeting to chloroplasts, we transiently overexpressed a fusion of the $44 \mathrm{~N}$-terminal residues to GFP in Arabidopsis leaf protoplasts and determined its location using confocal microscopy (Fig. 5). While GFP alone located outside of chloroplasts, which were visualized by chlorophyll fluorescence (Fig. 5a, e, i), GFP fused to the NPQ6 transit peptide co-localized with the chlorophyll fluorescence, indicating that the $\mathrm{N}$-terminal 44 residues are sufficient for chloroplast targeting and that the mature form of NPQ6 is a chloroplast protein (Fig. 5b, f, j).

\section{NPQ6 homologs in Arabidopsis}

A database search using the NPQ6 (At5g43050) amino acid sequence revealed two predicted Arabidopsis proteins, At1g65420 and At3g56830, with 34 and 35\% similarity, respectively, to NPQ6 (Fig. 6). The cloned full-length cDNA of Atlg65420 indicates that the Atlg65420 gene consists of two exons, and that the gene encodes a protein of 197 amino acids (GenBank accession number AY088215) (Fig. 7a). For the At3g56830 gene, only ESTs were available. Therefore, we did a RACE experiment and determined that the full-length At3g56830 coding region is interrupted by two introns and encodes a protein of 188 amino acids, which is identical to a recently cloned fulllength cDNA (GenBank accession number AK226187) (Fig. 8a). In addition, an alternatively spliced full-length cDNA sequence, encoding 243 amino acids, was also recently reported (GenBank accession number BX822814) although we could not find this form among our RACE products. Interestingly, the first intron in both At3g56830 transcripts has unusual GC-AG border sequences, while the

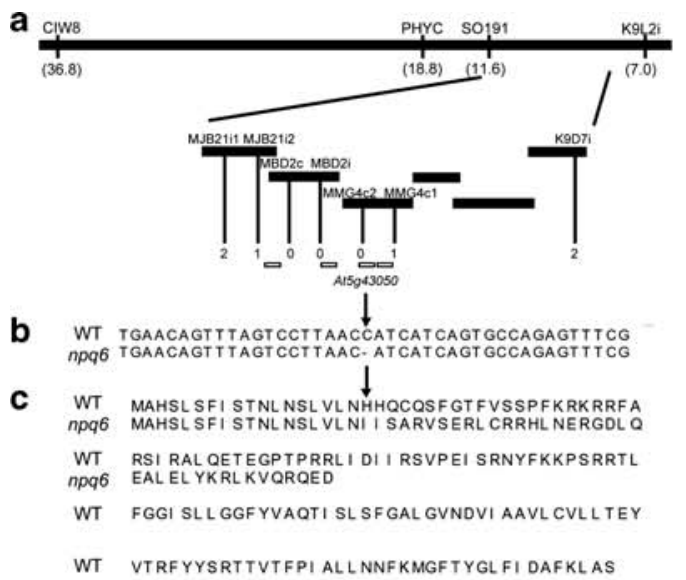

d
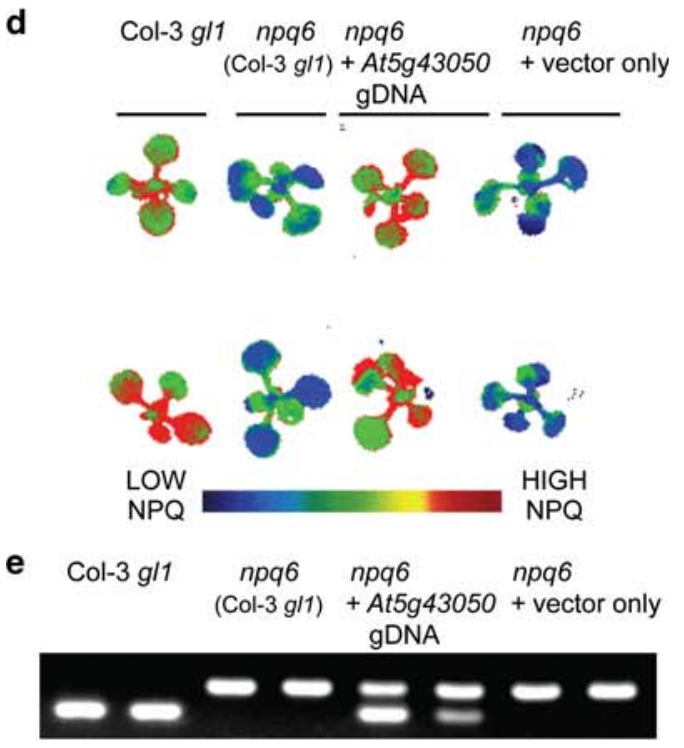

f

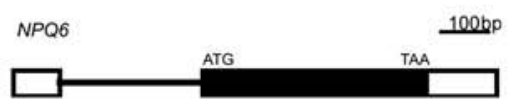

g
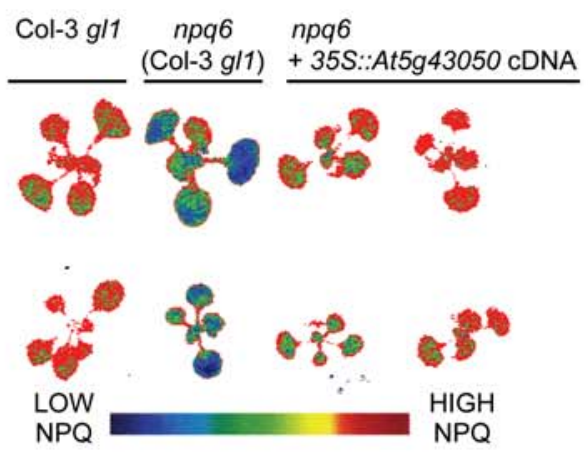

h

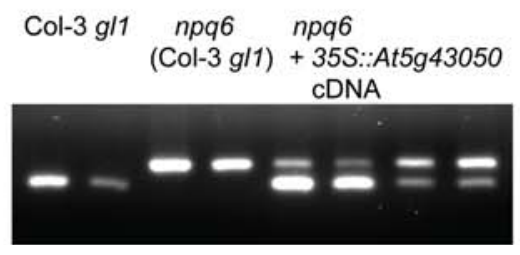



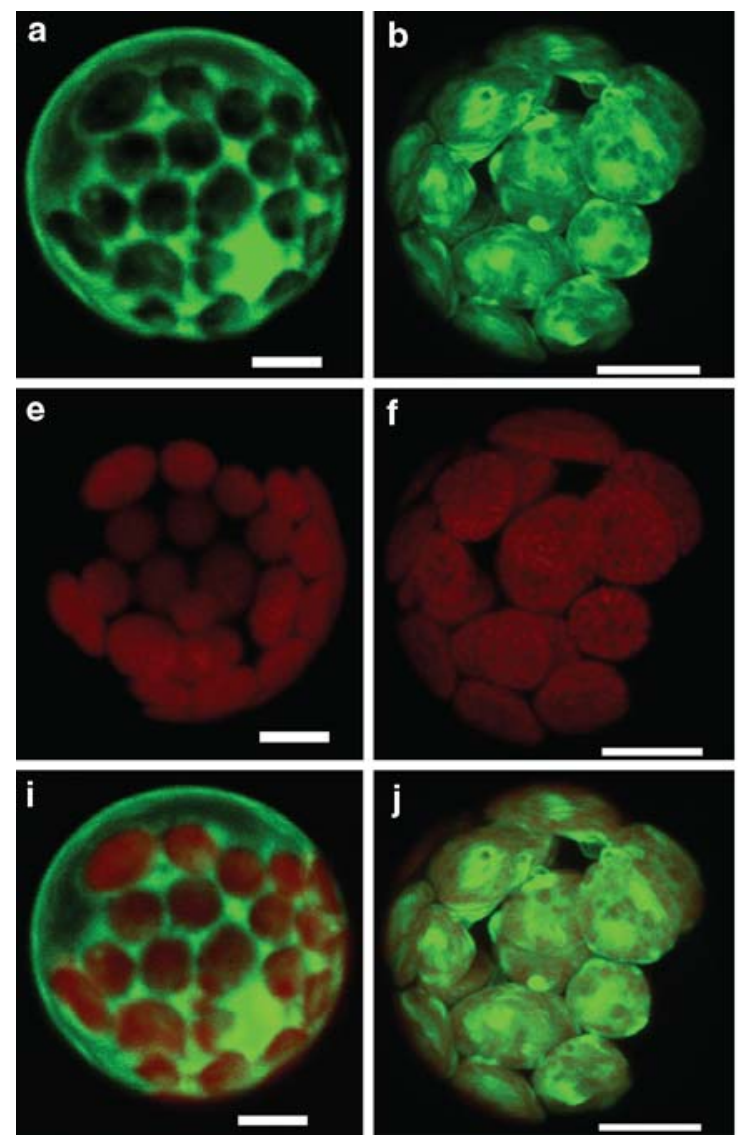

Fig. 5 Localization of NPQ6, NPQ7 and At3g56830. NPQ6 (b, f, j), NPQ7 (c, g, k) or At3g56830 (d, h, l) transit peptide-GFP fusion was transiently overexpressed in Arabidopsis leaf protoplasts. As a control, GFP alone $(\mathbf{a}, \mathbf{e}, \mathbf{i})$ was introduced to the protoplasts. Using

second intron has consensus GT-AG splice sites (Fig. 8a). Besides the unusual intron border, five different types of $5^{\prime}$ upstream regions (UTRs) were identified. It was predicted that four of them encode short translation products in the $5^{\prime}$ UTR, and that in the type IV and the type V transcripts, the short upstream ORFs even pass the start codon of the At3g56830 transcript, which might affect its translation efficiency (Fig. 8a).

Like NPQ6, At1g65420 and At3g56830 were predicted to have N-terminal chloroplast transit peptides. The sizes of the predicted chloroplast transit peptides are 68 and 59 residues for At1g65420 and At3g56830, respectively. The predicted transit peptides of At1g65420 and At3g56830 were fused to GFP, and then each fusion construct was introduced into Arabidopsis leaf protoplasts. Confocal fluorescence microscopy showed that the transit peptides of At1g65420 (Fig. 5c, g, k) and At3g56830 (Fig. 5d, h, l) are each sufficient for chloroplast localization of GFP. Therefore, the NPQ6 homologs, At1g65420 and At3g56830, are both likely to be chloroplast proteins.
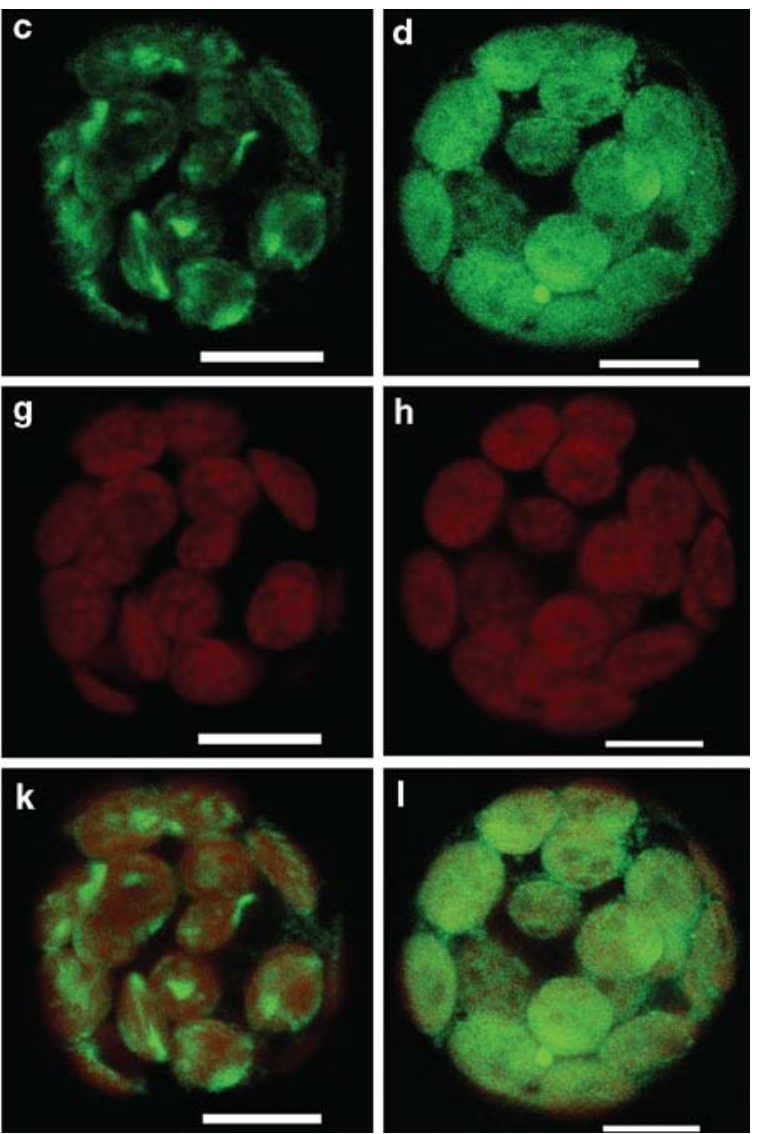

confocal microscopy, green fluorescence signal (a-d) and chlorophyll fluorescence $(\mathbf{e}-\mathbf{h})$ were detected. The superimposed images of green fluorescence and chlorophyll fluorescence (i-l) indicated that NPQ6, NPQ7 and At3g56830 are chloroplast proteins. Scale bar $10 \mu \mathrm{m}$

Without the predicted chloroplast transit peptides, both At1g65420 and At3g56830 are 129 amino acids long (Fig. 6a). In the predicted mature forms, the NPQ6 protein shows $31 \%$ identity and $41 \%$ similarity to At1g65420, and $32 \%$ identity and $40 \%$ similarity to At3g56830. At1g65420 and At3g56830 are 45\% identical and 53\% similar to each other. Among these three proteins, amino acid sequences in the C-terminal region are most highly conserved (Fig. 6a).

Interestingly, the At1g65420 protein is annotated as a hypothetical chloroplast open reading frame 20-like (YCF20-like) protein with three potential transmembrane domains (Swiss-Prot accession number O80813). The YCF20 gene was originally found as a plastid open reading frame (ORF) without known function in red algae such as Aglaothamnion neglectum and Galdieria sulphuraria (Apt and Grossman 1993; Valentin et al. 1992) (Fig. 6b, c). YCF2O genes are present in fully sequenced chloroplast genomes (Fig. 6b) of red algae including Porphyra purpurea (Reith and Munholland 1995), Cyanidium caldarium (Glöckner et al. 2000), and Cyanidioschyzon merolae (Ohta 
Fig. 6 Alignment of YCF20 amino acid sequences. a Amino acid sequence alignment of predicted mature forms of NPQ6, NPQ7 and At3g56830. The size of the chloroplast transit peptide of each protein was predicted by using the ChloroP program. Following removal of the transit peptides, the amino acid sequences were aligned using Clustal_X, and then were displayed using BOXSHADE. b Unrooted Neighbor-Joining tree of YCF20 proteins. Species names are shown with gene localization in chloroplast $(C P)$, nucleus $(N)$ or nucleomorph $(N M)$. Green algae and higher plants are displayed as green, cyanobacteria as blue, red algae as red, cryptophyte as brown. c C-terminal end amino acid sequence alignment of YCF20 proteins a

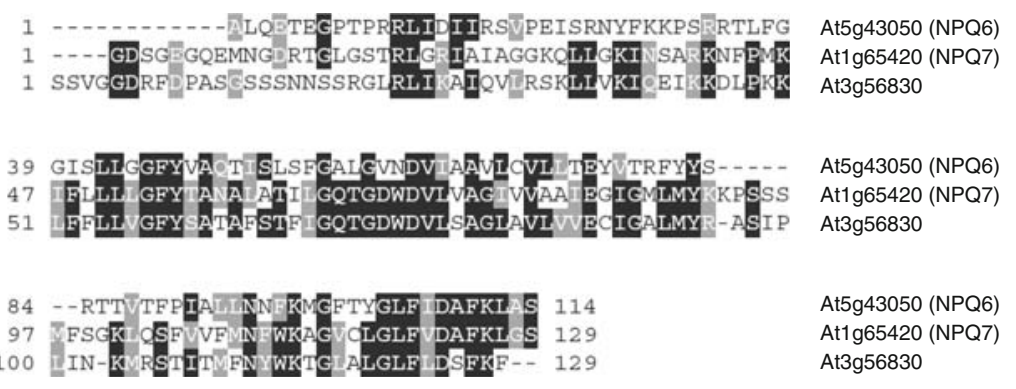

b

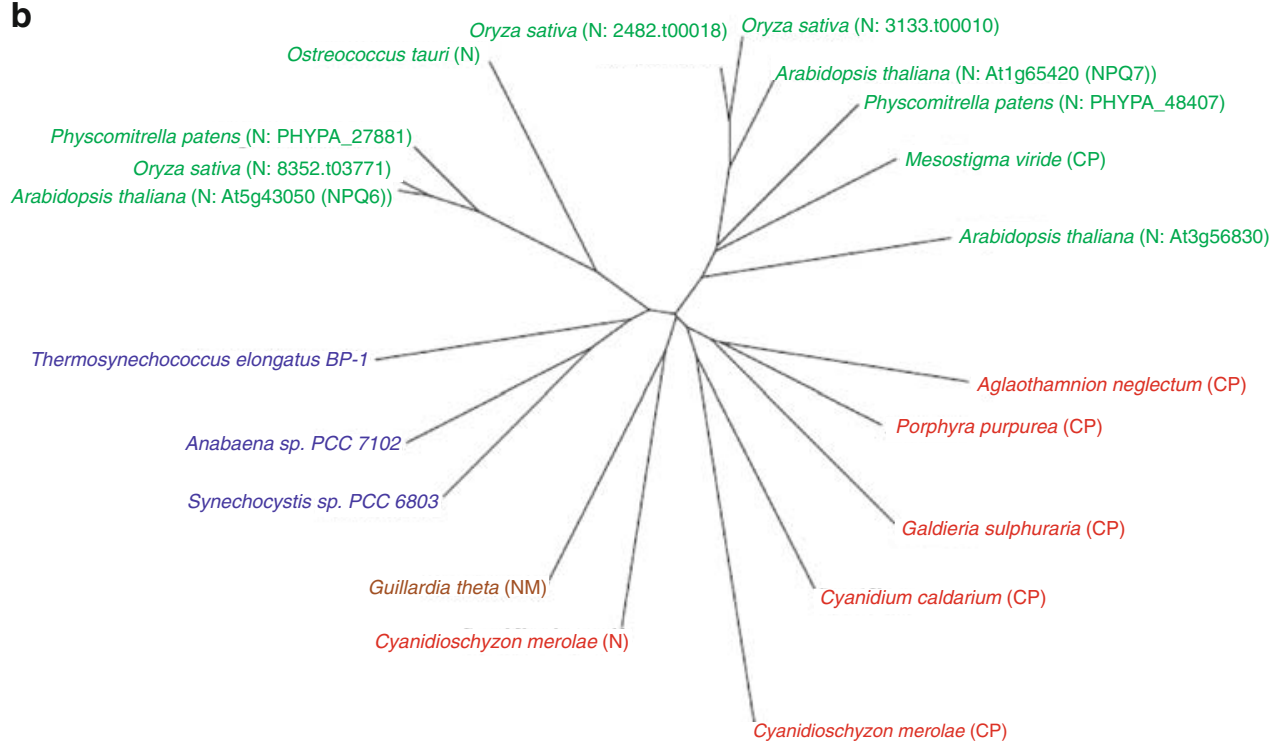

C

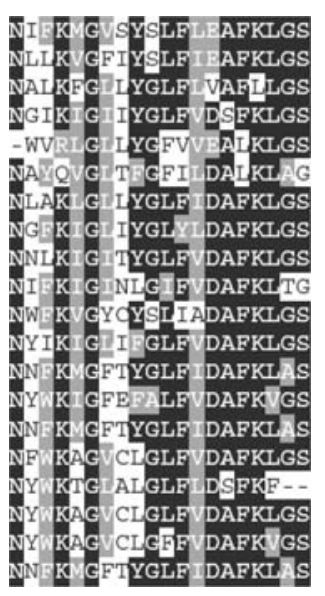

et al. 2003) and of the cryptophyte Guillardia theta (Douglas and Penny 1999), which is derived from secondary endosymbiosis of a red alga. Besides chloroplast genomes, YCF20-like genes are present in the completely sequenced nuclear genome of Cyanidioschyzon merolae (Matsuzaki et al. 2004) and in the nucleomorph genome of G. theta (Douglas et al. 2001; Matsuzaki et al. 2004), and interestingly, the predicted proteins are in the same clade (Fig. 6b). The G. theta nucleomorph is a highly reduced red algal nucleus remaining after secondary endosymbiosis. YCF20-like genes have been found in almost all sequenced cyanobacterial genomes, including for example Synechocystis sp. PCC 6803 (Kaneko et al. 1996), Anabaena sp. PCC 7120 (Kaneko et al. 2001), and Thermosynechococcus elongatus BP-1 (Nakamura et al. 2002) (Fig. 6b). In Prasinophyte green algae, the YCF2O gene seems to be present either in the chloroplast genome or in the nuclear genome, because the $Y C F 20$ gene of Mesostigma viride is present in the chloroplast genome (Lemieux et al. 2000), whereas that of Ostreococcus tauri 
a

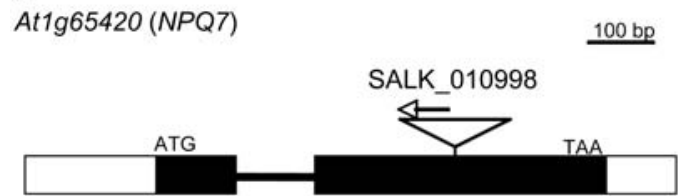

b

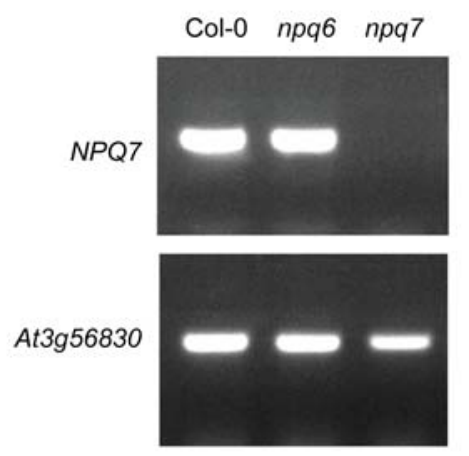

c

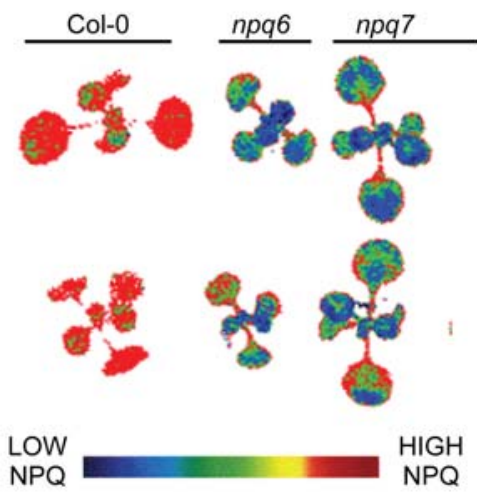

d
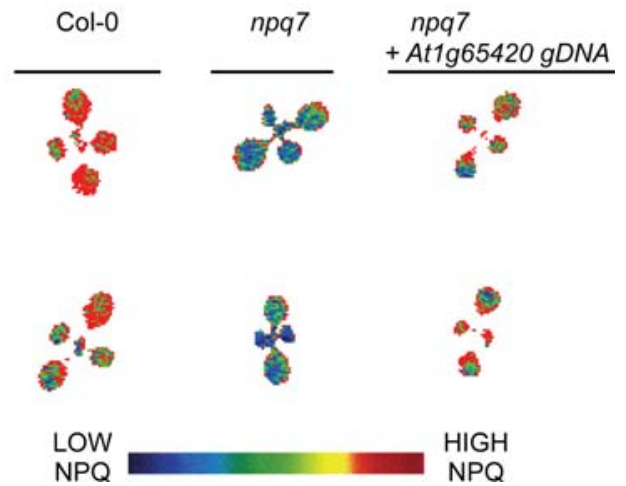

Fig. 7 Identification of $n p q 7$ knockout mutant and its low NPQ phenotype. a Schematic view of the T-DNA insertion site in SALK_010998. Back and white bars exons and UTRs of NPQ7, respectively, and the line is an intron. The T-DNA insertion site is indicated by an inverted triangle. The position of left border (LB) primer is displayed above the triangle. b RT-PCR results with genespecific primers for At1g65420 following reverse transcription. Expression levels of At3g56830 were used as a loading control. c, d Digital video imaging of chlorophyll fluorescence of $n p q 7$ and of the complemented line. The pseudo-color image shows the low NPQ phenotype (blue) in $n p q 6$ and $n p q 7$ with wild-type level of NPQ (red) in Col-0 and in $n p q 7$ transformed with the genomic DNA region encompassing the At1g65420 (NPQ7) gene

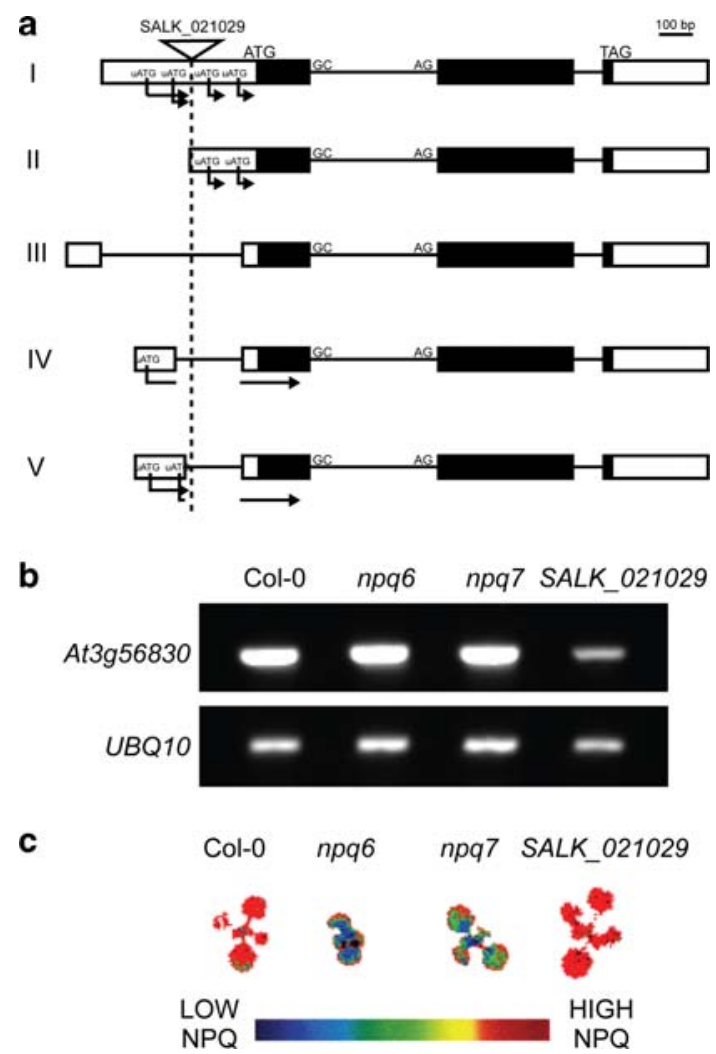

Fig. 8 Characterizaton of the At3g56830 T-DNA insertion. a Five types (I through V) of cDNA of At3g56830 were identified by RACE. White and black bars represent UTRs and coding regions, respectively, and the lines indicate introns. The position of unusual intron border sequences (GC) is indicated. The positions of possible translation start sites in the UTR $(u A T G)$ are marked along with their possible lengths of translation, which are proportional to the lengths of the lines. The T-DNA insertion site in SALK_021029 is marked with the inverted triangle. b RT-PCR results with genespecific primers for At3g56830 and for $U B Q 10$ as a loading control in the homozygous SALK_021029 line compared to Col-0, npq6 and $n p q 7$. c Digital video imaging of chlorophyll fluorescence of SALK_021029 and of Col-0, npq6 and npq7. The SALK_021029 line showed a wild-type level of NPQ (red), which was similar to Col0 . In contrast, low NPQ levels in $n p q 6$ and $n p q 7$ appeared blue

is in the nuclear genome (Derelle et al. 2006) (Fig. 6b). However, in higher plants including rice, genes encoding YCF20 reside only in nuclear genomes. Moreover, the genes are present as multiple copies. For example, there are two genes in Physcomitrella patens (PHYPADRAFT_27881 and PHYPADRAFT_48047) and three nuclear loci in rice (2482.t00018, 3133.t00010 and 8352.t03771), similar to the situation in Arabidopsis (Fig. 6b). NPQ6 and its close homologs in rice and Physcomitrella patens are in the same clade as the YCF20like protein of Ostreococcus tauri, whereas At1g65420, At3g56830, and their closest homologs in rice and Physcomitrella patens are in that the same clade as the YCF20like protein of Mesostigma viride. Interestingly, At3g56830 
branched out earlier than Mesostigma viride in the clade (Fig. 6b).

These members of the YCF20 protein family (Pfam accession number PF04483) (Bateman et al. 2004) contain Domain of Unknown Function 565 (DUF565) as a 56-59 amino acid residue domain in their C-terminal ends. The very end ( $\sim 20$ residues) of the $\mathrm{C}$-terminal region is highly conserved in nearly all of the YCF20 and YCF20-like proteins (Fig. 6c). In particular, the last seven residues (D/ E)AFKLGS, were found in most of the YCF20 family members (Fig. 6c), suggesting that this C-terminal domain is functionally important. The C-terminus of NPQ6 has only one conservative substitution (DAFKLAS) compared to the consensus, and At1g65420 has an exact match (DAFKLGS). In contrast, the At3g56830 amino acid sequence ends with a less conserved peptide (DSFKF).

\section{Reverse genetics of Atlg65420 and At3g56830}

To determine whether other YCF20-like proteins in Arabidopsis are also involved in NPQ, we identified a T-DNA line (SALK_010998) with an insertion in the second exon of the Atlg65420 gene (Fig. 7a). PCR screening with a TDNA left border (LB) and a gene-specific primer was used to identify a homozygous line for the T-DNA insertion. In the homozygous line, complete interruption of At1g65420 gene expression was confirmed by the lack of amplification of the Atlg65420 transcript in RT-PCR, whereas a control RT-PCR with gene-specific primers for At3g56830 amplified its transcript (Fig. 7b).

Interestingly, the Atlg65420 knockout mutant line showed a low NPQ phenotype in the video imaging system (Fig. 7c), and detailed chlorophyll fluorescence measurements confirmed that the NPQ levels in the knockout line are lower than those of the wild-type segregants, which were obtained from the PCR screening (Fig. 1b). Based on this phenotype, we have assigned the name $N P Q 7$ to the Atlg65420 gene. The results of crosses between $n p q 7$ and the wild-type (Col-0) indicated that the low NPQ phenotype of $n p q 7$ is due to a single recessive mutation caused by the T-DNA insertion (Table 2). Furthermore, introduction of the wild-type $N P Q 7$ gene complemented the $n p q 7$ insertion mutation and restored the wild-type NPQ phenotype (Fig. 7d). These results indicate that a loss of function mutation affecting another Arabidopsis YCF20like protein, NPQ7, also impairs NPQ.

To investigate further the low NPQ phenotype in $n p q 7$, we compared the photosynthesis-related phenotypes of $n p q 7$ with Col-0. Like $n p q 6$, the $n p q 7$ mutant did not show any visible phenotype in controlled environmental growth conditions (data not shown). In addition, $F_{\mathrm{v}} / F_{\mathrm{m}}$ of $n p q 7$ was almost identical to that of the wild-type, and the xanthophyll cycle pigment $(\mathrm{V}+\mathrm{A}+\mathrm{Z})$ pool size was not significantly different (Table 1). In addition, an ANOVA test showed that there were no statistically significant differences in de-epoxidation state between $n p q 7$ and Col-0 $(P>0.01)$ or in interactions between light treatment and genotypes $(P>0.01)$ (Fig. 3b), whereas there were significant treatment effects $\left(P=8.84 \times 10^{-11}\right)$ (Fig. 3b). These results were similar to those of $n p q 6$. However, $\Phi_{\mathrm{PSII}}$ in $n p q 7$ was slightly higher than in Col-0 (Fig. 2b), and there were significant differences in the chlorophyll $a+b$ contents and chlorophyll $a / b$ ratio between $n p q 7$ and Col-0 (Table 1). Chlorophyll $a+b$ contents in $n p q 7$ were higher than those of Col-0, whereas the chlorophyll $a / b$ ratio of the mutant was smaller than that of the wild-type. These results indicate that antenna size in $n p q 7$ may be bigger than in the wild-type.

In an effort to determine whether the third YCF20-like gene in Arabidopsis (At3g56830) also affects NPQ, we identified a homozygous T-DNA insertion line (SALK_021029) in which the $5^{\prime}$-UTR of the gene was disrupted (Fig. 8a). The homozygous insertion in the $5^{\prime}$-UTR caused reduced transcript levels (Fig. 8b), however, the At3g56830 knockdown mutant showed wild-type levels of NPQ in video imaging of chlorophyll fluorescence (Fig. 8c).

Overlapping functions of $N P Q 6$ and $N P Q 7$

In spite of the presence of multiple copies of YCF20-like genes in Arabidopsis, mutation of either $N P Q 6$ or $N P Q 7$ caused a low NPQ phenotype. We compared expression levels of NPQ6 and NPQ7 using the Arabidopsis eFP Browser (Supplementary Fig. 1), which showed that expression levels of $N P Q 6$ and $N P Q 7$ were similar to each other during plant development (fold differences $<1.5$ ). To investigate a possible overlapping function of NPQ6 and NPQ7 in NPQ, we generated an $n p q 6 n p q 7$ double mutant and determined its NPQ levels. We also isolated wild-type progeny and the $n p q 6$ and $n p q 7$ single mutants from from the segregating population of the $n p q 6 \times n p q 7$ cross in order to compare NPQ levels in a relatively homogeneous genetic background (all of them had a wild-type GL1 locus). Quantitative NPQ measurements showed that the NPQ level of the $n p q 6 n p q 7$ double mutant was lower than that of each single mutant (Fig. 1c). Thus, the $n p q 6$ and $n p q 7$ mutations seem to have additive effects on the low NPQ phenotype in the double mutant.

\section{Discussion}

Genes in the YCF20 family are present not only in chloroplast genomes of algae, but also in the nucleus (or nucleomorph) of some algae (Fig. 6b, c). In addition, YCF20-like genes are found in cyanobacteria and in the 
nucleus of some algae and higher plants. The broad phylogenetic distribution and genomic locations of YCF2O genes are consistent with the hypothesis that $Y C F 20$ originated in cyanobacteria and became a plastid gene in algae through primary and secondary endosymbiosis (Archibald and Keeling 2002). A YCF2O gene still resides in the chloroplast of the primitive green alga Mesostigma viride (Lemieux et al. 2000), however, YCF20 genes were not found in the chloroplast genomes of Euglena gracilis (Hallick et al. 1993) and several green algae, including Chlamydomonas reinhardtii (Maul et al. 2002), Chlorella vulgaris (Wakasugi et al. 1997), Nephroselmis olivacea (Turmel et al. 1999), and Ostreococcus tauri (Derelle et al. 2006), and also not in chloroplast genomes of higher plants (Martin et al. 2002). This distribution suggests that multiple losses of YCF2O from the chloroplast genome have occurred in the green lineage.

In the case of $O$. tauri and plants, it is clear that the YCF2O gene has relocated to the nucleus through the process of endosymbiotic gene transfer, and subsequent gene duplications in plants have resulted in multiple paralogs in the nuclear genome as found in Arabidopsis (Fig. 6). In contrast, the YCF20 gene appears to have been completely lost in the green algae Chlamydomonas reinhardtii and Chlorella vulgaris, for which nuclear genome sequences are available. The finding that $Y C F 20$ genes are present in both the chloroplast and nucleomorph of Guillardia theta and in both the chloroplast and nucleus of Cyanidioschyzon merolae supports the idea of gene relocation from chloroplast to nucleus, and these likely represent cases of chloroplast to nucleus gene transfers that are "in progress."

Despite the finding of $Y C F 20$ genes in a wide variety of cyanobacteria, algae, and plants, the function of these genes has not been previously identified experimentally. Here, through a combination of forward and reverse genetics, we have shown that mutations in two of the three YCF20-like genes in Arabidopsis affect qE, the regulated thermal dissipation of excess absorbed light energy in photosynthesis. The functions of these two genes, NPQ6 (At5g43050) and NPQ7 (At1g65420) overlap but are not simply redundant, because the single mutants are partially impaired in $\mathrm{qE}$ and the phenotype of the double mutant is additive (Fig. 1). Experiments that test whether overexpression of NPQ6 can suppress the $\mathrm{qE}$ defect of $n p q 7$, and vice versa, would be of help to understand the functional relationship between $N P Q 6$ and $N P Q 7$.

A T-DNA knockdown mutant affecting transcript levels of the third YCF20-like gene in Arabidopsis (At3g56830) showed wild-type levels of NPQ (Fig. 8c), suggesting that this gene might have a different function from NPQ6 and $N P Q 7$. Consistent with this possibility, At3g56830 seems to diverge from other higher plant members in the clade harboring NPQ7 (Fig. 6b), and the C-terminus of the predicted
At3g56830 gene product is not as highly conserved as in NPQ6 and NPQ7 (Fig. 6c). Expression of C-terminal fusions of a hemagglutinin tag to NPQ6 and NPQ7 were unable to complement the $n p q 6$ and $n p q 7$ mutations, respectively (data not shown), indicating that the $\mathrm{C}$-terminal domain of these proteins might be very critical for their function. On the other hand, it is possible that the At3g56830 knockdown affects the transcript level but not the protein level. Future analysis of a complete loss-offunction mutant induced by T-DNA insertion within the coding region of the At3g56830 gene might help to resolve whether or not its gene product is also involved in NPQ.

Although we have provided strong molecular genetic evidence that mutations affecting two chloroplast-localized YCF20-like proteins impair the $\mathrm{qE}$ component of NPQ in Arabidopsis, the exact molecular function of these proteins remains to be determined. YCF20-like genes are also found in cyanobacteria, but cyanobacteria lack $\mathrm{pH}$-dependent $\mathrm{qE}$ and have a completely different type of rapid NPQ that involves an orange carotenoid protein and quenching of excess excitation energy in phycobilisomes (Wilson et al. 2006). It is possible that the YCF20-like NPQ6 and NPQ7 proteins in Arabidopsis have evolved a new, specific function in $\mathrm{qE}$ that is distinct from the role of YCF20-like proteins in cyanobacteria. Alternatively, NPQ6 and NPQ7 might have a more general role in PSII function or organization that is shared by many oxygenic photoautotrophs and that somehow affects $\mathrm{qE}$ when disrupted in Arabidopsis. Our molecular genetic analysis of mutants affecting NPQ6 and NPQ7 represents an important first step toward understanding the function of YCF20-like proteins, and future biochemical characterization of NPQ6 and NPQ7 in Arabidopsis along with analysis of $y c f 20$ mutants in cyanobacteria will be necessary to elucidate the molecular details of how these proteins function in thermal dissipation and oxygenic photosynthesis.

Acknowledgments We thank Alba Phippard for technical support. This research was supported by the Chemical Sciences, Geosciences and Biosciences Division, Office of Basic Energy Sciences, Office of Science, U.S. Department of Energy, FWP number 449A449B.

Open Access This article is distributed under the terms of the Creative Commons Attribution Noncommercial License which permits any noncommercial use, distribution, and reproduction in any medium, provided the original author(s) and source are credited.

\section{References}

Alonso JM, Stepanova AN, Leisse TJ, Kim CJ, Chen H, Shinn P, Stevenson DK, Zimmerman J, Barajas P, Cheuk R, Gadrinab C, Heller C, Jeske A, Koesema E, Meyers CC, Parker H, Prednis L, Ansari Y, Choy N, Deen H, Geralt M, Hazari N, Hom E, Karnes M, Mulholland C, Ndubaku R, Schmidt I, Guzman P, Aguilar- 
Henonin L, Schmid M, Weigel D, Carter DE, Marchand T, Risseeuw E, Brogden D, Zeko A, Crosby WL, Berry CC, Ecker JR (2003) Genome-wide insertional mutagenesis of Arabidopsis thaliana. Science 301:653-657

Apt KE, Grossman AR (1993) The phycobilisome beta ${ }^{18}$ subunit gene of allophycocyanin is located on the plastid genome in Aglaothamnion neglectum (rhodophyta) and cotranscribed with an unidentified open reading frame. J Phycol 29:716-718

Archibald JM, Keeling PJ (2002) Recycled plastids: a 'green movement' in eukaryotic evolution. Trends Genet 18:577-584

Bailey S, Mann NH, Robinson C, Scanlan DJ (2005) The occurrence of rapidly reversible non-photochemical quenching of chlorophyll $a$ fluorescence in cyanobacteria. FEBS Lett 579:275-280

Baker NR (2008) Chlorophyll fluorescence: a probe of photosynthesis in vivo. Annu Rev Plant Biol 59:89-113

Barber J, Andersson B (1992) Too much of a good thing: light can be bad for photosynthesis. Trends Biochem Sci 17:61-66

Bateman A, Coin L, Durbin R, Finn RD, Hollich V, Griffiths-Jones S, Khanna A, Marshall M, Moxon S, Sonnhammer ELL, Studholme DJ, Yeats C, Eddy SR (2004) The Pfam protein families database. Nucleic Acids Res 32:D138-D141

Briantais J-M, Vernotte C, Picaud M, Krause GH (1979) A quantitative study of the slow decline of chlorophyll $a$ fluorescence in isolated chloroplasts. Biochim Biophys Acta 548:128138

Campbell D, Hurry V, Clarke AK, Gustafsson P, Öquist G (1998) Chlorophyll fluorescence analysis of cyanobacterial photosynthesis and acclimation. Microbiol Mol Biol Rev 62:667-683

Chiu W, Niwa Y, Zeng W, Hirano T, Kobayashi H, Sheen J (1996) Engineered GFP as a vital reporter in plants. Curr Biol 6:325330

Clough SJ, Bent AF (1998) Floral dip: a simplified method for Agrobacterium-mediated transformation of Arabidopsis thaliana. Plant J 16:735-743

Demmig-Adams B, Adams WW (1996) Xanthophyll cycle and light stress in nature: uniform response to excess direct sunlight among higher plant species. Planta 198:460-470

Demmig-Adams B, Adams W III, Barker D, Logan B, Bowling D, Verhoeven A (1996) Using chlorophyll fluorescence to assess the fraction of absorbed light allocated to thermal dissipation of excess excitation. Physiol Plant 98:253-264

Derelle E, Ferraz C, Rombauts S, Rouzé P, Worden AZ, Robbens S, Partensky F, Degroeve S, Echeynié S, Cooke R, Saeys Y, Wuyts J, Jabbari K, Bowler C, Panaud O, Piégu B, Ball SG, Ral J-P, Bouget F-Y, Piganeau G, De Baets B, Picard A, Delseny M, Demaille J, Van de Peer Y, Moreau H (2006) Genome analysis of the smallest free-living eukaryote Ostreococcus tauri unveils many unique features. Proc Natl Acad Sci USA 103:1164711652

Douglas SE, Penny SL (1999) The plastid genome of the cryptophyte alga, Guillardia theta: complete sequence and conserved synteny groups confirm its common ancestry with red algae. J Mol Evol 48:236-244

Douglas S, Zauner S, Fraunholz M, Beaton M, Penny S, Deng LT, Wu X, Reith M, Cavalier-Smith T, Maier UG (2001) The highly reduced genome of an enslaved algal nucleus. Nature 410:10911096

Emanuelsson O, Nielsen H, von Heijne G (1999) ChloroP, a neural network-based method for predicting chloroplast transit peptides and their cleavage sites. Prot Sci 8:978-984

Genty B, Briantais J-M, Baker N (1989) The relationship between quantum yield of photosynthetic electron transport and quenching of chlorophyll fluorescence. Biochim Biophys Acta 900:87-92

Glöckner G, Rosenthal A, Valentin K (2000) The structure and gene repertoire of an ancient red algal plastid genome. J Mol Evol $51: 382-390$
Hallick R, Hong L, Drager R, Favreau M, Monfort A, Orsat B, Spielmann A, Stutz E (1993) Complete sequence of Euglena gracilis chloroplast DNA. Nucleic Acids Res 21:3537-3544

Horton P, Ruban AV, Walters RG (1994) Regulation of light harvesting in green plants. Indication by nonphotochemical quenching of chlorophyll fluorescence. Plant Physiol 106:415420

Jander G, Norris SR, Rounsley SD, Bush DF, Levin IM, Last RL (2002) Arabidopsis map-based cloning in the post-genome era. Plant Physiol 129:440-450

Jung H-S, Niyogi KK (2009) Quantitative genetic analysis of thermal dissipation in Arabidopsis. Plant Physiol 150:977-986

Kaneko T, Sato S, Kotani H, Tanaka A, Asamizu E, Nakamura Y, Miyajima N, Hirosawa M, Sugiura M, Sasamoto S, Kimura T, Hosouchi T, Matsuno A, Muraki A, Nakazaki N, Naruo K, Okumura S, Shimpo S, Takeuchi C, Wada T, Watanabe A, Yamada M, Yasuda M, Tabata S (1996) Sequence analysis of the genome of the unicellular cyanobacterium Synechocystis sp. strain PCC6803 II: sequence determination of the entire genome and assignment of potential protein-coding regions. DNA Res 3:109-136

Kaneko T, Nakamura Y, Wolk CP, Kuritz T, Sasamoto S, Watanabe A, Iriguchi M, Ishikawa A, Kawashima K, Kimura T, Kishida Y, Kohara M, Matsumoto M, Matsuno A, Muraki A, Nakazaki N, Shimpo S, Sugimoto M, Takazawa M, Yamada M, Yasuda M, Tabata S (2001) Complete genomic sequence of the filamentous nitrogen-fixing cyanobacterium Anabaena sp. strain PCC 7120. DNA Res 8:205-213

Kasahara M, Kagawa T, Oikawa K, Suetsugu N, Miyao M, Wada M (2002) Chloroplast avoidance movement reduces photodamage in plants. Nature 420:829-832

Klimyuk V, Carroll B, Thomas C, Jones J (1993) Alkali treatment for rapid preparation of plant material for reliable PCR analysis. Plant J 3:493-494

Kovacs L, Damkjaer J, Kereiche S, Ilioaia C, Ruban AV, Boekema EJ, Jansson S, Horton P (2006) Lack of the light-harvesting complex CP24 affects the structure and function of the grana membranes of higher plant chloroplasts. Plant Cell 18:31063120

Lemieux C, Otis C, Turmel M (2000) Ancestral chloroplast genome in Mesostigma viride reveals an early branch of green plant evolution. Nature 403:649-652

Li X-P, Björkman O, Shih C, Grossman AR, Rosenquist M, Jansson S, Niyogi KK (2000) A pigment-binding protein essential for regulation of photosynthetic light harvesting. Nature 403:391395

Li Z, Wakao S, Fischer BB, Niyogi KK (2009) Sensing and responding to excess light. Annu Rev Plant Biol 60:239-260

Long SP, Humphries S, Falkowski PG (1994) Photoinhibition of photosynthesis in nature. Annu Rev Plant Physiol Plant Mol Biol 45:633-662

Martin W, Rujan T, Richly E, Hansen A, Cornelsen S, Lins T, Leister D, Stoebe B, Hasegawa M, Penny D (2002) Evolutionary analysis of Arabidopsis, cyanobacterial, and chloroplast genomes reveals plastid phylogeny and thousands of cyanobacterial genes in the nucleus. Proc Natl Acad Sci USA 99:12246-12251

Matsuzaki M, Misumi O, Shin IT, Maruyama S, Takahara M, Miyagishima SY, Mori T, Nishida K, Yagisawa F, Yoshida Y, Nishimura Y, Nakao S, Kobayashi T, Momoyama Y, Higashiyama T, Minoda A, Sano M, Nomoto H, Oishi K, Hayashi H, Ohta F, Nishizaka S, Haga S, Miura S, Morishita T, Kabeya Y, Terasawa K, Suzuki Y, Ishii Y, Asakawa S, Takano H, Ohta N, Kuroiwa H, Tanaka K, Shimizu N, Sugano S, Sato N, Nozaki H, Ogasawara N, Kohara Y, Kuroiwa T (2004) Genome sequence of the ultrasmall unicellular red alga Cyanidioschyzon merolae 10D. Nature 428:653-657 
Maul JE, Lilly JW, Cui L, dePamphilis CW, Miller W, Harris EH, Stern DB (2002) The Chlamydomonas reinhardtii plastid chromosome: islands of genes in a sea of repeats. Plant Cell 14:2659-2679

Maxwell K, Johnson GN (2000) Chlorophyll fluorescence: a practical guide. J Exp Bot 51:659-668

Müller P, Li X-P, Niyogi KK (2001) Non-photochemical quenching: a response to excess light energy. Plant Physiol 125:1558-1566

Müller-Moulé P, Conklin PL, Niyogi KK (2002) Ascorbate deficiency can limit violaxanthin de-epoxidase activity in vivo. Plant Physiol 128:970-977

Munekage Y, Takeda S, Endo T, Jahns P, Hashimoto T, Shikanai T (2001) Cytochrome $b_{6} f$ mutation specifically affects thermal dissipation of absorbed light energy in Arabidopsis. Plant $\mathrm{J}$ 28:351-359

Nakamura Y, Kaneko T, Sato S, Ikeuchi M, Katoh H, Sasamoto S, Watanabe A, Iriguchi M, Kawashima K, Kimura T, Kishida Y, Kiyokawa C, Kohara M, Matsumoto M, Matsuno A, Nakazaki N, Shimpo S, Sugimoto M, Takeuchi C, Yamada M, Tabata S (2002) Complete genome structure of the thermophilic cyanobacterium Thermosynechococcus elongatus BP-1. DNA Res 9:123-130

Neff MM, Turk E, Kalishman M (2002) Web-based primer design for single nucleotide polymorphism analysis. Trends Genet 18:613615

Nielsen H, Engelbrecht J, Brunak S, von Heijne G (1997) Identification of prokaryotic and eukaryotic signal peptides and prediction of their cleavage sites. Prot Eng 10:1-6

Niyogi KK (1999) Photoprotection revisited: genetic and molecular approaches. Annu Rev Plant Physiol Plant Mol Biol 50:333-359

Niyogi KK, Björkman O, Grossman AR (1997) Chlamydomonas xanthophyll cycle mutants identified by video imaging of chlorophyll fluorescence quenching. Plant Cell 9:1369-1380

Niyogi KK, Grossman AR, Björkman O (1998) Arabidopsis mutants define a central role for the xanthophyll cycle in the regulation of photosynthetic energy conversion. Plant Cell 10:1121-1134

Ohta N, Matsuzaki M, Misumi O, Miyagishima SY, Nozaki H, Tanaka K, Shin IT, Kohara Y, Kuroiwa T (2003) Complete sequence and analysis of the plastid genome of the unicellular red alga Cyanidioschyzon merolae. DNA Res 10:67-77

Reith M, Munholland J (1995) Complete nucleotide sequence of the Porphyra purpurea chloroplast genome. Plant Mol Biol Rep 13:333-335

Rozen S, Skaletsky HJ (2000) Primer3 on the WWW for general users and for biologist programmers. In: Krawetz SSM (ed) Bioinformatics methods and protocols: methods in molecular biology. Humana Press, Totowa, pp 365-386

Shikanai T, Müller-Moulé P, Munekage Y, Niyogi KK, Pilon M (2003) PAA1, a P-type ATPase of Arabidopsis, functions in copper transport in chloroplasts. Plant Cell 15:1333-1346

Thompson J, Gibson T, Plewniak F, Jeanmougin F, Higgins D (1997) The CLUSTAL_X windows interface: flexible strategies for multiple sequence alignment aided by quality analysis tools. Nucleic Acids Res 25:4876-4882

Turmel M, Otis C, Lemieux C (1999) The complete chloroplast DNA sequence of the green alga Nephroselmis olivacea: Insights into the architecture of ancestral chloroplast genomes. Proc Natl Acad Sci USA 96:10248-10253

Valentin K, Maid U, Emich A, Zetsche K (1992) Organization and expression of a phycobiliprotein gene cluster from the unicellular red alga Cyanidium caldarium. Plant Mol Biol 20:267-276

Wakasugi T, Nagai T, Kapoor M, Sugita M, Ito M, Ito S, Tsudzuki J, Nakashima K, Tsudzuki T, Suzuki Y, Hamada A, Ohta T, Inamura A, Yoshinaga K, Sugiura M (1997) Complete nucleotide sequence of the chloroplast genome from the green alga Chlorella vulgaris: the existence of genes possibly involved in chloroplast division. Proc Natl Acad Sci USA 94:5967-5972

Wilson A, Ajlani G, Verbavatz J-M, Vass I, Kerfeld CA, Kirilovsky D (2006) A soluble carotenoid protein involved in phycobilisomerelated energy dissipation in cyanobacteria. Plant Cell 18:9921007

Yamamoto HY, Nakayama TOM, Chichester CO (1962) Studies on the light and dark interconversions of leaf xanthophylls. Arch Biochem Biophys 97:168-173 